\title{
Reaching faculty during the summer Taking inspiration from the blogosphere
}

ibrarians at Western Carolina University have performed scholarship-focused summer outreach to the teaching faculty for many years, primarily via in-person workshops. Since faculty often focus on scholarship rather than instruction during summers, our emphasis on research and publication was timely and appropriate. However, the in-person research workshops were poorly attended, as faculty who do not teach summer courses often do not come to campus.

In order to increase faculty engagement with the library over the summer, we decided to restructure our outreach and move it online. The inspiration came from the lifestyle website Apartment Therapy's "January Cure," a series of weekly assignments intended to help readers spruce up their homes in the new year. ${ }^{1}$ The January Cure series breaks the daunting task of cleaning your home into manageable chunks, and the writers describe the tasks in ways that make you want to get your hands (or rubber gloves) dirty! Even if you don't complete a recommended step, the instructions leave you with the skills to tackle the job in your own time.

We decided to emulate that approach by taking a project and breaking it into simple online tasks that the faculty could complete each week or whenever they chose.

\section{Planning and topic selection}

After deciding on this delivery model, we brainstormed and refined the topic for the series. One of the librarians suggested training faculty in Google Scholar, and others were interested in sharing services, such as the institutional repository. Both goals could be accomplished in the series format, along with other tasks that would help faculty members build their professional presence online. The series was titled "Boost Your Scholarly Profile." ${ }^{2}$

The group discussed several possible subtopics and ultimately selected seven to deliver as tasks. We then created a research guide using Springshare's LibGuides software to serve as the homebase for the information. Each task had its own subpage, and one task was released roughly each week throughout the summer. Contributors developed their tasks in draft mode. After a quick review by colleagues, the guide was published for external audiences. Here are descriptions of the seven tasks.

- Task 1: Google Yourself. The first task guided participants through a quick audit

Heidi Buchanan is research and instruction librarian, email: hbuchanan@wcu.edu, Liz Skene is digital initiatives librarian, email: emskene@wcu.edu, Ann Hallyburton is research and instruction librarian and liaison to the health and human sciences librarian, email: ahallyb@wcu.edu, and Sarah Steiner is head of research and instruction services, email: sksteiner@ wcu.edu, at Western Carolina University

(c) 2016 Heidi Buchanan, Liz Skene, Ann Hallyburton, and Sarah Steiner 
of their online presence. The audit helped participants identify gaps in the information they found online (for example, had they made a curriculum vitae available?) so they would know which subsequent tasks they wanted to focus on. ${ }^{3}$

- Task 2: Update or create your Google Scholar profile. This task featured a Creative Commons-licensed tutorial video on creating a Google Scholar profile that we borrowed from the Laurier University Library. ${ }^{4}$ The page also included a written step-by-step guide to signing up for a pro-

file, making it Hunter LiBrary

public, explor- RESEARCH GUIDES

ing citations, and making updates.

- Task 3: Create your scholarly ID.

A scholarly ID can help to prevent scholars with similar or identical names from being conflated online, so we chose that as our next topic. We decided to guide faculty through creating an ORCID account, which associates each

Boost Your Scholarly Profile!: Welcome

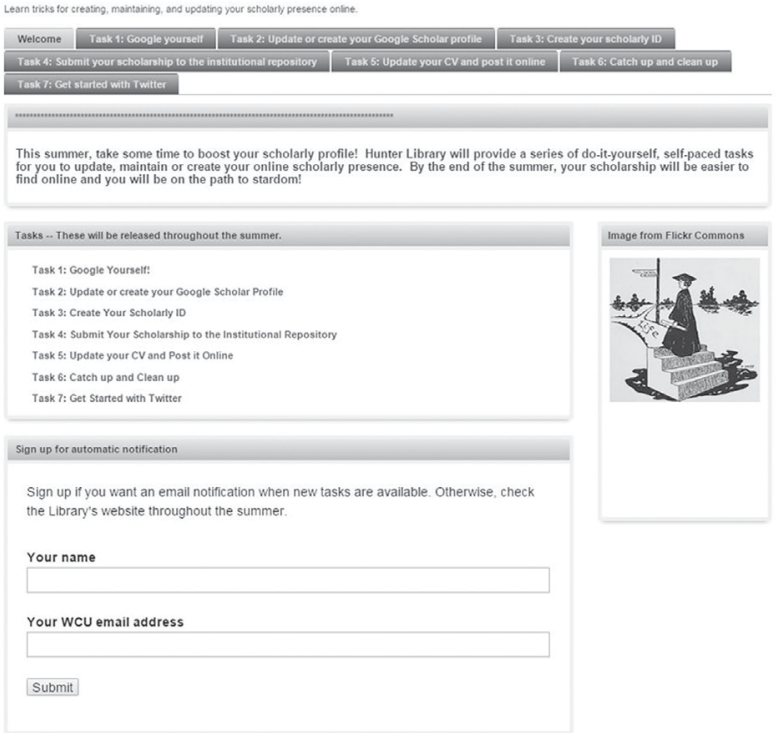

Screenshot of the landing page for the Boost Your Scholarly Profile LibGuide. View this article online for more detailed image. for this page of the guide. this task was to highlight the library's institutional repository and some brief facts about open access. The library's digital initiatives librarian created and described a seamless way for faculty to submit their scholarly work and research data to the repository

- Task 5: Update your CV and post it online. This task provided participants with free tools and information to help them post a curriculum vitae online either as a website (using Wix, Weebly, or WordPress) or a PDF document (using Dropbox). The subpage

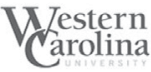

of the research guide also featured links to example CVs for various disciplines for inspiration.

- Task 6: Catch up and clean up. In the penultimate week, we gave participants some free time to complete previous tasks and perform some basic housekeeping. They were encouraged to update professional acindividual with a scholarly ID number. The guide page for this task outlined steps for ORCID registration and adding publications via import from Google Scholar, integration with CrossRef (we added a short video clip for this option), or manual addition of past publication information. The guide also showed users how to create a Research ID in Web of Science and associate it with their ORCID account.

- Task 4: Submit your scholarship to the institutional repository. The focus of counts (e.g., LinkedIn, ResearchGate, Academia.edu), remove outdated information (e.g., a website at a former institution), and double-check privacy settings on social media. The subpage on the research guide presented a short review of all of the previous tasks.

- Task 7: Get started with Twitter. The final task explained advantages of having a professional Twitter presence and took participants through the process of setting up an account and sending out tweets. 


\section{Promotion and participation}

The library's subject liaisons emailed an invitation to participate to each of their assigned departments. Announcements about the series and each subtask were posted on the library's Facebook page, news blog, and Twitter feed. In the spirit of the Apartment Therapy model, librarians created a form in the research guides software so that people who wanted to be notified of each weekly task could sign up to receive alerts.

Though only seven people signed up for automatic email notifications, the guide received 277 visits. We were pleased because the virtual turnout far exceeded the small numbers at our in-person workshops.

\section{What worked}

The weekly task format was an interesting and exciting way to distribute information. Each new task provided participants with the opportunity to explore a particular tool or piece of information, and it allowed us to highlight and link to issues already covered in our existing research guides. For example, some of the institutional repository information included in the series was already available in the library's open access research guide, but having the information as a stand-alone task helped to promote those related services.

The weekly release structure was meant to help participants and content creators stay on task. The release dates for each topic were not strict, so the librarians who created the content had some flexibility. Dividing the tasks among participating librarians provided each person with a clear assignment, a set date range for completion of the task, and a relatively small amount of work. Using an interdepartmental call for participation allowed librarians from all the library's departments to contribute to the project, so it ultimately represented services and expertise from throughout the library.

The profile-raising aspect of the series and its focus on scholarly success kept the emphasis of the project on the faculty members. Scholarship is a topic that is intrinsically interesting to faculty, and they have plenty of extrinsic motivation for participation. The tasks provided a manageable, concrete path toward an increased online scholarly profile: an area of growing importance within academia. Additionally, with this structure, participants were able to pick and choose which tasks they found interesting or useful enough to complete.

\section{Future plans and other applications of this model}

For the next online series, we plan to provide more opportunities for would-be participants to sign up for notifications. We also plan to substantially increase our marketing efforts by leveraging existing publicity outlets like the university's weekly online newsletter.

For individuals interested in adopting this serial format, it should translate well for a variety of audiences and subjects. For instance, the model might be adapted for use in a series geared toward graduate students across disciplines. Rather than scholarly profiles, the series could guide students through their orientation to citation managers, advanced database searching, interlibrary loan, or other services particular to teaching and laboratory assistants.

The serial format would also be useful to librarians who wish to align the release of discipline-specific library or information literacy instruction to an evolving semester-long course or degree-length program. As students progress within a course or a program, a librarian might add a new module or a new task that corresponds to real-time progress in the classroom or program. The series sections could then be updated and reused in successive semesters or with the next year of students in the program.

Gaming aspects of this approach could be emphasized via the integration of incentives, which participants could earn for completing a certain number of tasks (and perhaps, providing documentation of completion). If a library decides to employ incentives, librarians should consider selecting goods or other enticements particular to the demographics 
(location, discipline, etc.) of the target audience. For example, a library coffee shop gift certificate may appeal to someone who works or takes courses near the library, but be wholly unappealing to an instructor who participates only in distance courses. This type of polite competition may improve participation while adding an air of fun to the tasks.

Soliciting task ideas from faculty (or whomever the series intended audience might be), whether via focus group or poll, could provide insight into the topics or types of activities that the audience needs. The assessment would also function as a form of free, informal marketing for the series, and could serve to increase buy-in.

\section{Tips for similar projects}

- Get your colleagues on board. One of the strengths of this project was the cross-departmental collaboration of the librarians. However, there's nothing to say that you can't work with other departments on campus such as IT, the grants office, or other academic units.

- Brainstorm a list of topics. Our tasks had a mix of library and nonlibrary services, both of which we plan to expand on next time. What services aren't getting enough use (institutional repository, data management, etc.)? What sorts of questions do you regularly field (citation management, etc.)? What misconceptions can you address (open access publishing, altmetrics, etc.)?

- Choose the task frequency. Once you have a list of topics, you can decide how often to release new tasks. Do you want to have a two-week blitz of activity, a summer of weekly tasks, or a year-long focus with monthly activities?

- Decide on a platform. We used LibGuides for our project as it is both flexible and familiar to the librarians who participated. Possibly Tumblr, WordPress, or a page within your library's CMS would work better? You could even do a podcast series, though it may not be as riveting as the Serial podcast. Look for platforms that provide the ability to work collaboratively, can accommodate an increasing amount of content, and offer a way to permanently save the page, if you desire.

- Promote it early. Although our tasks were released during the summer, the spring semester was the best time to promote. Faculty were still on campus, they were still checking their emails, and they were still feeling optimistic about the amount of work they were going to accomplish over the summer.

- Remind people often. For the next online series, we plan to remind faculty that they can sign up for notifications any time throughout the process. During the 2015 implementation, individuals signed up for notifications immediately after the initial marketing email, but not later.

\section{Final thoughts}

This series presented an exciting, evolving way to provide virtual outreach to faculty. The built-in anticipation as new topics became available, the opportunity for collaboration among librarians within all the library's departments, and the focus on promotion of faculty research made this a positive experience for everyone involved. We would appreciate hearing about the experiences of other librarians who try similar projects.

\section{Notes}

1. Apartment Therapy, "January Cure." www.apartmenttherapy.com/collection/january-cure-2015-468 (accessed August 25, 2015).

2. Hunter Library, "Boost Your Scholarly Profile," http://researchguides.wcu.edu /scholarlyprofile.

3. Extra reading material included "How to Change Your Name and Keep Your Professional Identity" by Dorie Clark, Harvard Business Review, December 9, 2014.

4. Laurier University Library, "Show Your Research Impact with a Google Scholar Profile," YouTube video, 3:09, June 6, 2014 (accessed April 15, 2015), https://youtu.be /EQKPWo9qK7s. $\boldsymbol{n}$ 